\title{
ARTICLES
}

\section{Harmonizing Public and Private International Law: Implications of the Apple vs. Samsung IP Litigation}

\section{Sung Pil Park ${ }^{*}$}

IP litigations over mobile digital devices are soaring in many jurisdictions. Based on the observation that the same or closely related infringement claims over the IP rights embedded in a single digital product have been raised in multiple jurisdictions, some literature and legislative proposals suggest that an international jurisdiction over such litigations are necessary. This article aims to explore practical roadmaps to establish public international "conflict of laws" that can serve administering IP dispute resolution among MNCs. The author will start by reviewing both public international laws on IPRs including the Paris Convention, PCT, the Geneva Convention, the TRIPs, and their private counterparts. Institutional aspects of the WTO and the WIPO administering such as public international IP laws will also be examined. Agreeing with the proposed idea of establishing 'public' private international IP laws, this article will propose a more practical roadmap to establish time and cost efficient IP dispute resolution mechanism: the IP5 Collaboration Model.

\section{Keywords}

MNCs, IP, Apple-Samsung IP Litigation, Paris Convention, Berne Convention, PCT, TRIPS, EPC, IP5 Collaboration Model

* Professor Invitavit of Law at Korea Advanced Institute of Science and Technology ("KAIST") Graduate School of Future Strategy. LL.B./M.A. (SNU), LL.M./J.S.D.(Northwestern). Member of Michigan Bar. ORCID: http://orcid. org/0000-0002-7778-4814. The author may be contacted at: sppark@kaist.ac.kr/Address: Graduate School of Future Strategy, KAIST, 291 Daehak-ro, Yuseong-gu, Daejeon 305-701 Korea.

DOI: http://dx.doi.org/10.14330/jeail.2014.7.2.03 


\section{Introduction}

Multinational Corporations ("MNCs"), especially those in the IT industry, are pushing digital revolution hard by providing mobile digital devices ("MDDs") such as smartphones and tablets enabling their customers to connect from anywhere to everywhere around the globe. MDDs stand on the pinnacle of human intelligence that have accumulated throughout history. The more sophisticated MDDs are, the more valuable the intellectual property rights ("IPRs") become in protecting creative ideas and aesthetic features embedded in such devices. ${ }^{1}$

Reflecting this trend, litigations among MNCs over IPRs embodied in MDDs are soaring in many jurisdictions. In such litigations, the same or closely related infringement claims over the IPRs embedded even in one MDD are being filed in multiple jurisdictions simultaneously. ${ }^{2}$ A noticeable example is on-going AppleSamsung IP litigation. No tribunal in the world asserts its extraterritorial jurisdiction ("ETJ") over such transnational issues, which, once exercised, could facilitate time and cost efficient dispute resolution for all parties involved.

Competition among MNCs is becoming fiercer as more sophisticated technologies and higher-end product designs emerge and so the negative impact on social welfare of such global scale IP war is huge. It is important for the international community to come up with ideas to lessen the juridical inefficiencies, saving the MNCs resources for further innovation. With this goal, some scholars and practitioners have proposed several sets of principles to activate the ETJ rules for efficient IPR dispute resolution. On the other hand, although MNCs are by nature private entities, size and scope of their economic, social, and sometimes even political influence, they have reached a level that requires some elevated treatment in international law aspects.

The primary objective of this research is to discuss the practicality of this method. Together, it will also tackle the possibility of expanding the dispute settlement mechanism ("DSM") of the World Trade Organization ("WTO”). This paper is composed of five parts including Introduction and Conclusion. Part two will show the general picture of the Apple-Samsung IP litigations. Part three will investigate the harmonization of public and private international laws on the IP. Part four will discuss the critical questions regarding the multi-jurisdiction of the IP cases and

1 The term IPR is used interchangeably with intellectual property ("IP") in this article, which is customary among academics and practitioners.

2 In this article, such IPR disputes are referred to as "multijurisdictional IP disputes." 